\title{
Invasive Meningococcal Disease: A Review
}

\author{
Rashna D Hazarika
}

\section{Abstract}

Background: Invasive meningococcal disease (IMD) is a potentially fatal disease occurring all over the world. It affects predominantly young children, adolescents and young adults. However, even today cases are missed and there may be a delay in diagnosis and treatment leading not only to a fatal outcome but also to large scale epidemics.

Materials and methods: An extensive review of literature was done to describe the history, microbiology, global epidemiology, transmission and risk factors, pathogenesis, clinical features, management, prognosis, care of relatives and close contacts, prevention by the current vaccines available in the world and in India.

Results: Invasive meningococcal disease was first described in 1805 in Sweden. Subsequently periodic epidemics continue to occur all over the world. Globally it is present in more than 80 countries. Currently 12 known serotypes are described with a complex microbiology which helps the bacteria to not only survive in the human nasopharynx but also to adhere to and invade the meninges and the blood stream and present as meningitis, meningococcemia or both. Due to its capacity to produce various toxins and ability to survive destruction by the host immune system, it produces a number of clinical manifestations in a short time. Being potentially fatal, death in such patients can occur in a matter of hours. Microbiological diagnosis is difficult as the organism is fastidious and requires special conditions for growth and can explain the poor microbiological results worldwide. However attempts to culture the bacteria should be made from all available sites such as cerebrospinal fluid, blister fluid, blood and even skin biopsy specimen. The cornerstone of management is aggressive treatment with antibiotics, and other supportive care. Complications are common during the course of the infection and one must anticipate and tackle them aggressively and at the appropriate time. A large number of sequelae can occur in spite of optimal management. Prophylactic antibiotics in the care-givers and relatives is extremely important for short term protection. Long term protection of the community as well as of care-givers and close relatives is by vaccination. A number of effective vaccines have been developed over the years for the prevention of this deadly infection. Vaccine cost remains a major hindrance to universal vaccination.

Conclusion: Invasive meningococcal disease exists all over the world. It is important to be able to correctly recognize these patients for early and aggressive management. Prevention by vaccination remains the best public health measure to tackle this deadly infection.

Keywords: Invasive meningococcal disease, Meningitis, Meningococcemia, Neisseria, Purpura fulminans, Shock.

Pediatric Infectious Disease (2019): 10.5005/jp-journals-10081-1215

\section{INTRODUCTION}

Invasive meningococcal disease (IMD) is a rapidly progressive serious disease with varied presentations. It poses a major public health threat because of its global distribution, inherent potential for causing major epidemics predominantly among very young children, and also the adolescents and young adults, and because of the high case-fatality rate and morbidity in survivors. Globally, it is present in more than 80 countries. ${ }^{1}$ The disease pattern varies widely by region. Epidemic meningococcal disease occurs commonly in sub-Saharan Africa (also designated as the "meningitis belt") and many parts of Asia and India. Early and prompt antibiotic treatment along with supportive therapy is needed. The outcome of the disease depends on how fast the patient was brought for medical care ("house to hospital time"), and also on how fast the first dose of antibiotic was administered ("door to needle time"). Clinicians need to be on the alert and look out for meningococcal infections as the incidence of IMD is rising along with a global reduction in the incidence of both Hemophilus influenzae (H. influenzae) and pneumococcal meningitis following the introduction and use of the $H$. influenzae and pneumococcal vaccines across the globe.

\section{History}

Epidemic meningococcal disease was first described during an outbreak with 33 deaths in the vicinity of Geneva, Switzerland, by Vieusseux. ${ }^{2}$ Periodic epidemics in young children and military
Department of Pediatrics and Intensive Care, Rigpa Children's Clinic, Guwahati, Assam, India

Corresponding Author: Rashna D Hazarika, Department of Pediatrics and Intensive Care, Rigpa Children's Clinic, Guwahati, Assam, India, Phone: +919435012999, e-mail: rashnadass@gmail.com

How to cite this article: Hazarika RD. Invasive Meningococcal Disease: A Review. Pediatr Inf Dis 2019;1(3):95-107.

Source of support: Nil

Conflict of interest: None

recruits continued to occur throughout the 19th century. Its intracellular description was first given by the Italian pathologists Marchiafava and Celli in 1884 in a cerebrospinal fluid (CSF) sample. ${ }^{3}$ It was initially known as Diplococcus intracellularis meningitis. A therapy with serum from immunized horses was used by Jochmann in Germany and Flexner in the United States at the beginning of this century (1908) and helped to reduce case-fatality rates from 100 to $30 \% .{ }^{4}$ Antimcrobials like sulfonamides in 1937 helped in further drastic reduction of case-fatality rates. In addition to this, sulfonamides began to be used to eradicate the carrier state and thus reduce the epidemics. By 1963, an epidemic in two military bases in California could not be aborted by sulfonamide prophylaxis because of the occurrence of sulfonamide-resistant Meningococcus. This triggered vaccine development from selected meningococcal

() The Author(s). 2019 Open Access This article is distributed under the terms of the Creative Commons Attribution 4.0 International License (https://creativecommons. org/licenses/by-nc/4.0/), which permits unrestricted use, distribution, and non-commercial reproduction in any medium, provided you give appropriate credit to the original author(s) and the source, provide a link to the Creative Commons license, and indicate if changes were made. The Creative Commons Public Domain Dedication waiver (http://creativecommons.org/publicdomain/zero/1.0/) applies to the data made available in this article, unless otherwise stated. 
capsular polysaccharides. Various vaccines are now available against certain serotypes of the organism.

\section{NeISSERIA MENINGITIDIS-MICROBIOLOGY}

The genus Neisseria was named after Albert Neisser who first observed the diplococcus in leukocytes in urethral exudates from patients who had gonorrhea in $1879 . .^{5}$ Of the various species of Neisseria, which cause disease in humans, $N$. gonorrhoea and $N$. meningitidis cause significant disease in men. Genomic sequencing has categorized N. meningitidis as a-proteobacteria related to Bordetella, Burkoholderia, Kingella, and Methylomonas and more distantly related to Vibrio, Haemophilus, and Escherechia coli. ${ }^{6}$ Neiserria meningitidis, the causative organism for all forms of meningococcal disease, is an intracellular, aerobic, nonmotile organism (Fig. 1). It harbors two enzymes-oxidase enzyme and catalase enzyme. Neiserria meningitidis grows best in a humid atmosphere with $5-10 \%$ carbon dioxide and a temperature of about $89.6-98.6^{\circ} \mathrm{F}$, $\mathrm{pH}$ of 7-7.5. The organism can be cultured in blood agar as well as chocolate agar media where they grow as colonies measuring 1-2 $\mu \mathrm{m}$ in size (Fig. 2). Microscopically, the bacteria are seen as gram-negative cocci typically in pairs (diplococci) and occasionally

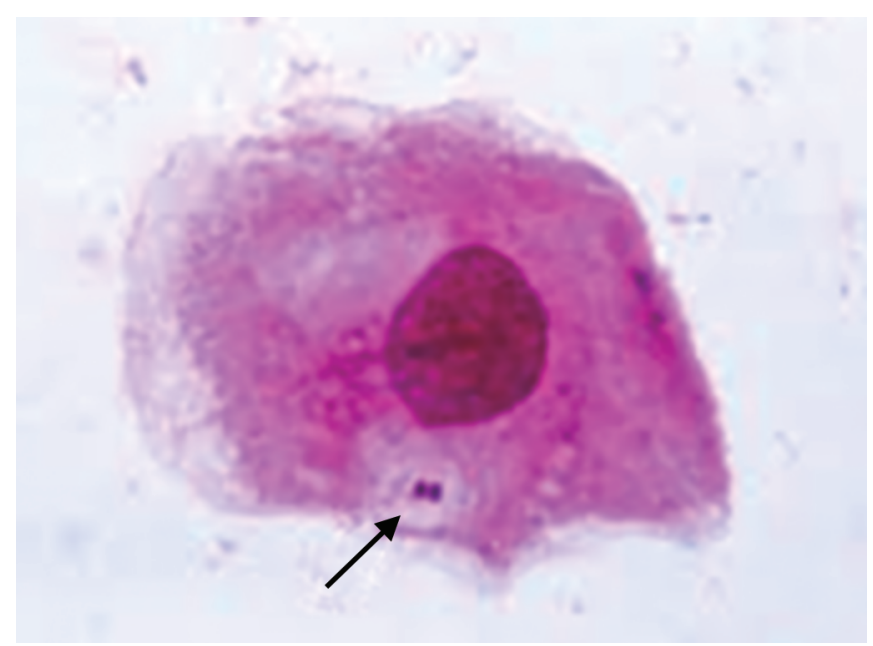

Fig. 1: Intracellular meningococci in tetrads or clusters. The bacterium possesses a cytoplasmic inner membrane, a thin peptidoglycan layer and an outer membrane made up of proteins, phospholipids, and lipo-oligosaccaride (LOS) (Fig. 3). It further contains a polyphosphate loosely attached to the surface and a polysaccharide capsule. Meningococci can be divided based on the structural differences in the polysaccharide capsule into 12 serotypes designated as $A, B, C, E, H, I, K, L, W, X, Y, Z$. Most infections are caused by serotypes $A, B, C, Y$, and $W-135 .{ }^{7}$ The capsular polysaccharides induce specific bactericidal antibodies and hence used for vaccine production except for the B-polysaccharide which is poorly immunogenic. ${ }^{5}$ An interesting phenomenon that exists in meningococci is the ability to exchange between meningococci, the genetic material responsible for the synthesis of the capsular polysaccharide. ${ }^{8}$ Thus, serogroup B can switch to $\mathrm{C}$ or vice vers $a .{ }^{9}$ Neiserria meningitidis also expresses two different classes of pili (class I or II), which are antigenically and structurally different. During infection, pili undergo rapid phase shifts and antigenic variation. ${ }^{10}$ Adhesion to epithelial and endothelial cells is caused by pili, and they impart tissue tropism. ${ }^{11}$ The electrostatic repulsion between the negatively charged mucosal surfaces is overcome by pili. Pili also play a role in the acquisition of homologous and heterologous DNA from the environment. ${ }^{12}$ The trimeric proteins present in the outer membrane of the meningococci provide channels or porins, allowing low-molecular nutrients to diffuse through the outer membrane. Neiserria meningitidis expresses two porins simultaneously: a class I protein, or Por A (44-47 kDa), and either a class II (40-42 kDa) or class III (37-39 kDa) protein, Por B. Por $A$ is cation-selective, whereas class II or III, Por B, is anion-selective. The antigenic differences between class I and class II proteins are used for serotyping meningococci. ${ }^{13}$ The outer membrane of $N$. meningitidis also contains an opacity protein, a class $\mathrm{V}$ protein (26-30 kDa) that has five variants, and from none-to-all variants of the opacity protein may be expressed by a single strain. These opacity proteins can undergo antigenic variation during natural infection and help in attachment of bacteria to the tissues where CD66e and heparin sulfate proteoglycan (HSPG) act as receptors. ${ }^{14,15}$ Another protein designated as class IV protein is found on the outer membrane and is reduction modifiable protein (Rmp) and increases in molecular weight on treatment with a reducing agent. This protein is immunologically conserved, and the Rmp antibodies interfere with the bactericidal activity of antibodies directed to other
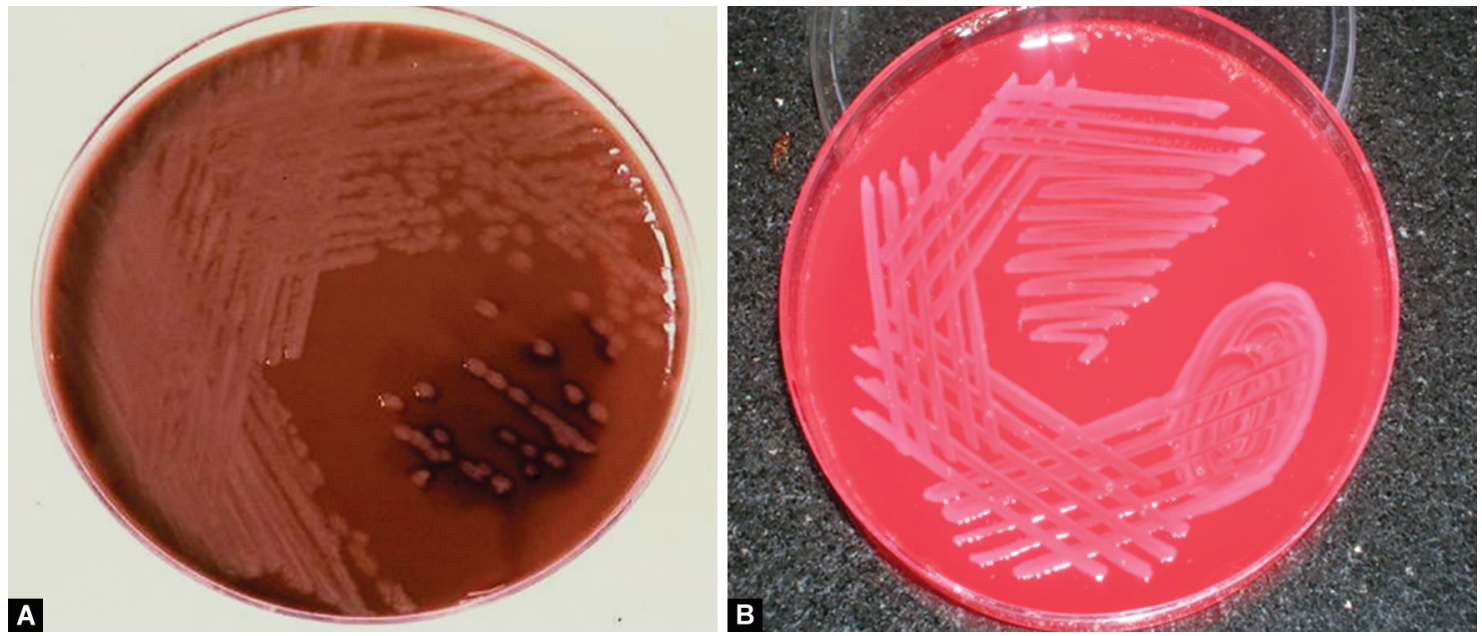

Figs 2A and B: (A) Chocolate agar plate; (B) Blood agar plate culture showing colonies of $N$. meningitidis 


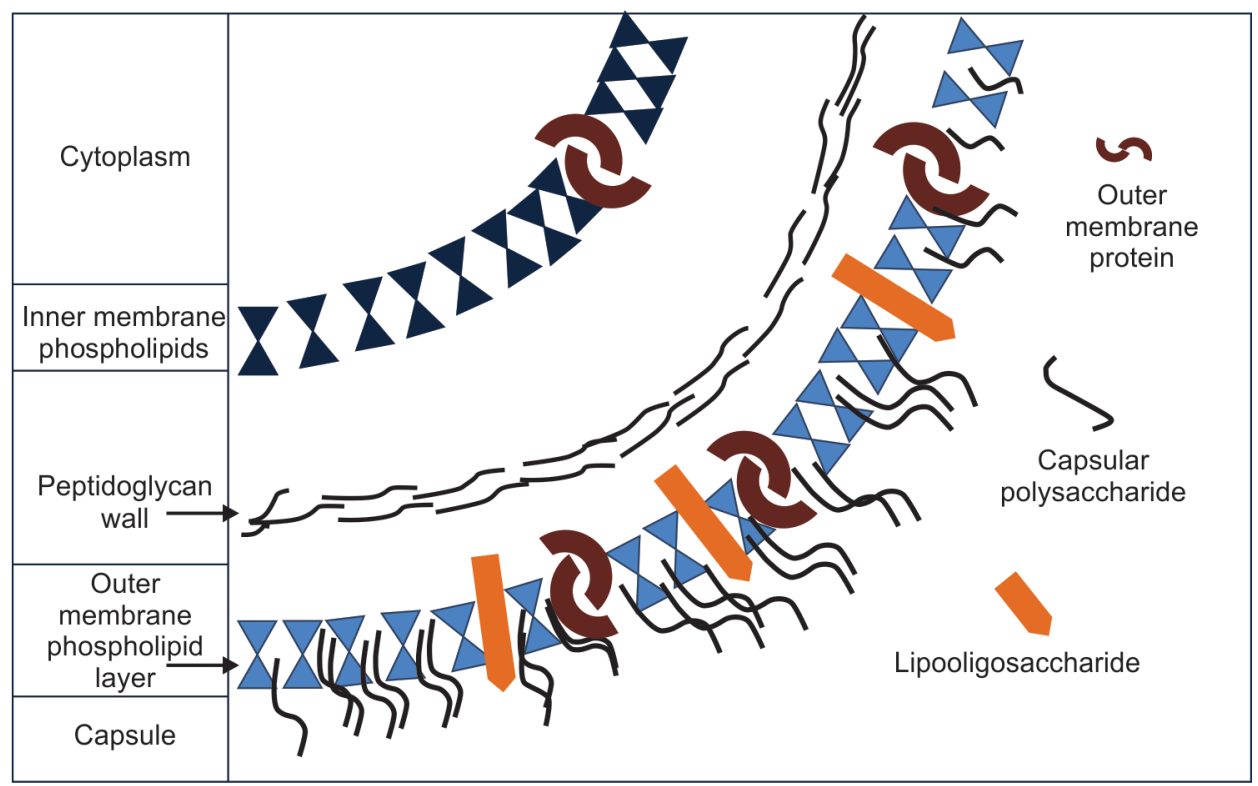

Fig. 3: Structure of N. meningitidis cell wall

surface antigens and are therefore known as blocking antibodies. ${ }^{5}$ Approximately $50 \%$ of the outer membrane consists of LOS. Lipooligosaccharide consists of a core of lipid A and short sugar chains of 8-12 saccharide units. The LOS sugars undergo high-frequency phase and antigenic variation during the course of infection and are again used for immunotyping of the meningococci. ${ }^{16}$ Vesicles, which occur as blebs, are shed by the neisserial outer membrane continuously. These blebs contain DNA, protein, and high levels of LOS, including lipid A. The LOS in these blebs is implicated in the onset of shock once the bacteria gain entrance into the circulation. ${ }^{17}$

Based on the serologic methods to detect antigenic differences on four surface antigens, $N$. meningitides can be phenotypically classified into four types: capsular polysaccharide, epitopes on outer membrane proteins of classes II and III, epitopes on class I outer membrane, and LOS epitopes. Meningococcal serogroup, serotype, and subserotype characterization are of great value in epidemiologic surveillance. Serotyping is also important for vaccine development.

Genes involved in polysaccharide biosynthesis and cell surface translocation are found to be clustered at a single chromosome locus termed cps. A complete nucleotide sequencing of cps loci encoding serogroups $\mathrm{A}-\mathrm{C}, \mathrm{W}$, and $\mathrm{Y}$ has been elucidated. Genomic data for other serogroups are also being identified, and additional data using multilocus sequence type (MLST) are being done these days. ${ }^{18}$ In India, molecular characterization of group I isolates has shown a phylogenetic relationship among strains of $N$. meningitidis isolated in Delhi and other geographical areas by MLST to belong to the clonal complex (CC) ST-5/subgroup III and MLST sequence 4789, which is closely related to sequence type 8428 from Bangladesh. ${ }^{19}$

\section{Global Epidemiology}

Meningococcal disease occurs worldwide as endemic disease. ${ }^{20}$ Globally, it has been now recognized as the main etiological agent of bacterial meningitis beyond infancy and in young adults. ${ }^{21}$ Different patterns of epidemiological behavior of meningococci are recognized, and these may be endemic, hyperendemic, epidemic, and pandemic. Globally, more than 80 countries are affected by the diseases caused by infection with $N$. meningitidis. ${ }^{1}$ Annually, about 1.2 million cases of invasive infection occur, of which 135,000 deaths are related to IMD. ${ }^{1}$ The serogroups A, B, C, Y, and W-135 are responsible for $90 \%$ of meningococcal infections, and of these serogroups, A, B, and C account for most cases of meningococcal disease throughout the world. Serogroups $A$ and $C$ predominate in Asia. ${ }^{22}$ Currently, the most important cause of endemic disease in the developed countries is serogroup B, resulting in about $30-40 \%$ of infections in the United States and up to $80 \%$ of infections in the European countries and Australia. ${ }^{22,23}$ Group W135 disease has become increasingly important and has been related to the Hajj pilgrimage since the late $1990 \mathrm{~s}^{24}$ Epidemic rates of meningococcal disease vary from $<1-3 / 100,000$ in many developed countries to as high as $10-25 / 100,000$ in some developing countries. ${ }^{4}$ These different attack rates reflect the different pathogenic properties of $N$. meningiditis strains and different socioeconomic, environmental, and climatological conditions. Irrespective of the serogroup involved, meningococcal disease is often seasonal in nature. Serogroups $A$ and $C$ disease increases during the dry season in Africa, whereas serogroups $B$ and $C$ peak during the winter months in the developed countries. The largest and most frequently recurring outbreaks have been in the semiarid area of sub-Saharan Africa for the last 100 years, otherwise known as the "meningitis belt". ${ }^{25}$ The meningitis belt in Africa was first described by Lapeyssonnie in 1963 when he described a sub-Saharan region, stretching from Ethiopia to Senegal, characterized by periodic large epidemics of meningococcal meningitis. ${ }^{26}$ The "meningitis belt" is made up of dry grassland and scrubs and is bounded in the north by the Sahara desert and in the south by humid savannah and rain forest. The area itself is dry most of the year, and the characteristic epidemics occur during the dry season. ${ }^{21}$ The largest outbreak ever reported occurred in the meningitis belt in 1996, and the total number of cases reported to the World Health Organization (WHO) was 152,813 with 15,783 deaths. ${ }^{27}$ In Asia, many epidemics have occurred in the last 30 years. The largest epidemic originated in northern China and spread to the south and later globally in $1980 .{ }^{20}$ This epidemic was caused by two clones of serogroup A, one of which spread to India later on in $1983 .^{6}$ In India, outbreaks have 
occurred mostly in Delhi and Surat, and the last major epidemics occurred in 2008 in northeastern India in the states of Meghalaya and Tripura. The health status indicators from the National Health Profile 2016 and 2017 published by the Government of India have reported meningococcal disease from nearly all states in the country with the highest number of cases from West Bengal. ${ }^{28}$

As per the National Centre for Disease Control, ${ }^{29}$ India, an epidemic of meningococcal disease is predicted when:

- An attack rate of at least fivefold higher than that observed during previous years in the same area, or if the data for the same area are not available, an attack rate of at least fivefold higher than the rate in the similar areas of the country.

- An attack rate of probable or confirmed meningococcal disease surpasses 5 cases per 100,000 population (while working out the attack rate, the preceding 3 months could be considered. Attack rate should be applied to populations of a district, and estimation of attack rates in an entire country will usually fail to detect local/focal epidemics).

- Rising incidence of the disease (probable or confirmed) for three consecutive weeks in the same area also calls for immediate attention.

- Occurrance of even a single case in epidemiological settings such as nursery, hostels, military barracks, and jails needs immediate attention.

\section{Transmission and Risk Factors}

For an invasive disease to occur, at least four conditions have to be met. ${ }^{20}$ These conditions are as follows:

- Exposure to a pathogenic strain

- Colonization of the naso-oropharyngeal mucosa

- Passage through the mucosa, and

- Survival of the Meningococcus in the bloodstream.

Transmission occurs by direct contact or via droplets for a distance up to 1 meter ( $3 \mathrm{ft})$. Usually, the bacteria are transmitted from a nasopharyngeal carrier. ${ }^{30,31}$ Globally, the carriage rates of meningococci for healthy adults are described to be between $10 \%$ and $35 \% .{ }^{31}$ Individuals with close contact such as students, military recruits, and pilgrims have carriage rates approaching $100 \%{ }^{32}$ The survival of the bacteria in the air droplets is influenced by temperature, humidity, host defense, and bacterial factors. ${ }^{31}$ The naso-oropharyngeal mucosa in humans is the only known natural reservoir of $N$. meningitidis. However, it is not clear why certain strains colonize the naso-oropharyngeal mucosa and others do not, and is the subject of extensive research. Colonization occurs at the exterior surface of the mucosal cell and also intra-or subepithelially. The first step in colonization is a damage to the nasopharyngeal ciliated epithelium. This damage can be potentiated by either active or passive smoking, thus making the individual vulnerable to more invasive forms of the disease. Stressful events such as preceding viral infections also increase the chance of invasive disease. ${ }^{33}$ Serogroups A, B, and C are more invasive than other serogroups of meningococci.

\section{Pathogenesis}

Pathogenesis of meningococcal disease involves three steps:

- Host-pathogen interaction.

- Host immune response activation.

- Effect on various organ systems.

\section{Host-Pathogen Interaction}

This is the first step in the pathogenetic mechanisms, and this interaction goes through the following steps:

- Nasopharyngeal colonization.

- Invasion of the vascular compartments and meninges.

- Survival in the blood stream.

\section{Nasopharyngeal Colonization}

Meningococcus adheres specifically to the nonciliated epithelial cells of the nasopharynx. ${ }^{34}$ The adhesion of Meningococcus to the epithelial cells is facilitated by a number of adhesion factors. The major adhesions involved are pili and the opacity proteins (Opa and $\mathrm{Opc}$ ), and some minor adhesion factors belonging to the auto-transporter family of molecules. ${ }^{35,36}$ Major adhesions, i.e., pili and opacity proteins (Opa and $\mathrm{Opc}$ ), are expressed in abundance on the bacterial surface. The pili undergo a rapid extension and retraction, thus imparting a twitching motility to the bacteria. ${ }^{37}$ The pilus shaft is composed of pilin subunits such as Pil E, Pil S, PilC, and Pil Q. Pil C and Pil Q promote neisserial adhesions to host cells. Other pilins undergo distinct and post-translational modifications leading to pilin glycosylation, which may promote the secretion of soluble pilin subunits. ${ }^{35}$ Soluble pilin subunits competes with anti-pilus antibodies and host cell receptors, which further assist in the protection of the bacteria against immune challenge, as well as promoting spread by preventing further the bacterial adhesion at the original site of colonization. The opacity proteins (Opa and Opc) are expressed as outer-membrane proteins and impart the opacity to agar-brown colonies. The expressed Opa type can alter randomly as the genes encoding Opa proteins undergo frequent phase variation of expression. The meningococcal Opa proteins bind to various receptors such as carcinoembryonic antigenrelated cell-adhesion molecule 1 (CEACAM1), which is present on the epithelial and endothelial cells. Some meningococcal Opa proteins also interact with cell-surface-associated HSPGs present in the epithelial cell surface. The Opa proteins thus interact with the specific receptors and thus form a trimolecular complex with fibronectin and integrins and mediate adhesion and invasion of human endothelial cells. ${ }^{34}$ The minor adhesions such as neisserial adhesion $\mathrm{A}(\mathrm{Nad} \mathrm{A})$ interacts with human epithelial cells through protein-protein interactions and contribute to bacterial virulence as it is expressed by $50 \%$ of disease isolates compared to only $5 \%$ of strains from healthy individuals. ${ }^{34}$ Two other proteins known as Neisseria hia homologue $\mathrm{A}(\mathrm{nhh} A)$, and adhesion and penetration protein (app) are widely expressed in virulent $N$. meningitidis strains, and these help in adhesion and penetration of the Meningococcus into the nasopharyngeal epithelial cells. ${ }^{34}$ The encapsulated form of $N$. meningitidis is most common and the capsule helps in survival of the organism outside the host. ${ }^{38}$ It is however not unknown for acapsulate forms to pass from person to person over short distances or by direct contact. Meningococcal strains carried by asymptomatic individuals in nonepidemic situations may be capsulate or acapsulate, but in epidemic areas such as the sub-Saharan belt in Africa, carriage of the capsulate form is more commonly seen. ${ }^{31,39}$ Firm adhesion by pili helps in anchoring the meningococci firmly to the nasopharyngeal mucosa and prevents it from being washed away by the nasopharyngeal mucous flow. These capsulated meningococci, which escape removal by the nasopharyngeal mucous flow, and cause colonization, now undergo capsule down modulation and then bind to host receptors such as CEACAMs, HSPGs, and App. Acapsulate phenotypes engage 
more intimately with the epithelial cells via the outer membrane proteins Opa and Opc. After colonization in the epithelial cells of the nasopharygeal mucosae, the meningococci internalize via host receptor interactions and also by interacting with fibronectin and vitronectin (matrix proteins), and subcellular proteins such as a-actinin and traverse across the epithelium.

\section{Invasion into the Vascular Compartment and Meninges}

After internalization in the nasopharyngeal mucosae, the meningococci possibly enter the vascular compartment by gaining entry into the endothelial cells lying in close proximity to the mucosal epithelial tissues. Integrins and HSPGs, which are expressed on the basolateral surface of the endothelial cells, also aid the attachment and transport of the meningococci in a basal to apical direction to enter the vasculature. ${ }^{34}$

The entry of meningococci into the brain requires the bacteria to cross the blood-brain barrier (BBB) made of the choroid plexus in the ventricles and the capillary endothelia. Both are lined by the cells with tight junctions. The flow rate and shear stresses imposed on the meningococci in the microcirculation of the BBB determine the rate of adhesion of the meningococci to the brain vasculature. The areas of low blood flow and low shear stress allow more meningococci to adhere to the vasculature. ${ }^{40}$ On the other hand, pili play a major role in maintaining adherence to the endothelial cells in the areas with high flow, along with cytoskeletal rearrangements leading to a lipid microdomain formation that helps in resisting shearing forces once bacteria are bound. ${ }^{41}$ The bound meningococci are then internalized by the endothelial cells and transcytosed to further enter the meninges. The disruption of the intercellular junctions by pili-induced signaling in endothelial cells also enables meningococcal passage. ${ }^{42}$ Both the opacity proteins Opa and Opc also enhance bacterial adhesion and entrance into the meninges. ${ }^{34}$ Once the BBB is breached, meningococci release proinflammatory cytokines by interacting with the cells lining the leptomeninges and cause the inflammatory reactions resulting in meningitis.

\section{Survival in the Blood Stream}

In the blood stream, the meningococci encounter a number of host-killing mechanisms, like antibody/complement-mediated lysis and opsonophagocytic killing. Therefore, only the capsulated meningococci survive in the blood stream using a number of mechanisms described below. ${ }^{34}$ The amount of LOS on the surface of the meningococci influences the ability of the meningococci to resist host killing. ${ }^{43}$ Meningococci then recruit negative regulators of complement to promote serum resistance. Factor $\mathrm{H}$ recruitment is done by factor $\mathrm{H}$-binding protein (fHbp), a $27 \mathrm{kDa}$ lipoprotein expressed by all meningococci. The porin Por A also binds a complement regulator, $C 4$-binding protein, which increases serum resistance. Both Por $A$ and Por $B$ are also involved in bacterial uptake via rearrangement of the cytoskeleton. ${ }^{44}$ The Por $B$ localizes in the mitochondrial compartment and leads to anti-apoptotic effect on the epithelial cells and enhances the survival of the meningococci up on apoptotic stimuli. ${ }^{45}$ The formation and insertion of membrane attack complexes is prevented by vitronectin (a bacterial adhesion protein). Direct binding to vitronectin also helps the Opc-expressing bacteria to resist serum killing. The engagement of CEACAM by Opa-expressing meningococci may also lead to the meningococci escaping the process of killing by promotion of neutrophil cell death. ${ }^{34}$ Thus, the meningococci interact with several regulators of the complement pathways and increase their survival in the blood.

\section{Activation of the Host Immune System}

Once viable meningococci have reached the bloodstream, the degree of bacteremia and the host immune status determine the various forms of disease manifestations. In patients with low bacteremia, meningococci are cleared spontaneously, clinically perhaps mimicking a transient flu-like episode. ${ }^{46}$ In other patients in whom the bacteremia is not cleared, the clinical manifestations become overt. The severity of the manifestations depends on the continuing survival of the meningococci in the blood stream and the ability of the meningococci to multiply in large numbers. ${ }^{47}$ Immunoprotection in meningococcal infection is offered most effectively by development of specific antibodies. ${ }^{47}$ The complement pathway, i.e., the classical pathway through antibody production, alternate pathway through properidin, and the mannose binding lectin pathway are all important for protection against meningococcal disease. Endotoxin release appears to be the most important trigger for the host immune response, and the severity of meningococcal disease is directly proportional to the levels of circulating endotoxin. ${ }^{48}$ The property of meningococci to release blebs of the outer membrane vesicles is very characteristic, and these blebs are rich in endotoxin. The release of these characteristic blebs probably plays an important role in releasing large quantities of endotoxin into the bloodstream. ${ }^{49}$ These blebs can be visualized in the plasma and CSF in invasive forms of the disease. ${ }^{35}$ Patients with shock have meningococcal strains, which liberate more endotoxin than those from patients with benign chronic meningococcemia. ${ }^{50}$ Endotoxin responsiveness to cytokines produced during invasive disease is genetically determined and different among individuals. The endotoxin binds to circulating endotoxin binding proteins and thus causes increased binding of endotoxin to the macrophages and activates the macrophages and a large number of other inflammatory cells. The principle cellular receptor for endotoxin is CD14. ${ }^{51} \mathrm{~A}$ number of proinflammatory cytokines such as tumor necrosis factor a (TNF- $\alpha$ ) and interleukin $1 \beta$ (IL-1 $\beta$ ) are produced along with an increased production of interferon $\gamma$ by $T$ cells and natural killer cells. Neutrophils also contribute greatly to the inflammatory process by producing reactive oxygen species and degranulation resulting in the release of a large number of inflammatory proteins, proteases, and other enzymes that degrade tissues. ${ }^{47}$ These products are responsible for a number of effects on the various organ systems. A recent article gives an extensive discourse on the interaction between the meningococci and the host-complement system and how it can evade being killed once it is exposed to the immune responses. $^{52}$

\section{Effect on Various Organ Systems}

The meningococci, which survive the immune-mediated killing in the vascular compartment and meninges, result in various effects on the different organ systems. They are described below:

\section{Microvascular Injury in Meningococcal Sepsis}

The pathophysiological changes that occur in meningococcal septicemia are related to the major changes that occur in the finely regulated functions of the microvasculature. These highly specialized properties of the vascular endothelial surface such as regulation of vascular permeability are lost during the inflammatory process. Four basic processes affecting the vasculature are as follows: 
Increased vascular permeability: Degradation of endothelial surface proteins by enzymatic reactions and loss of the surface endothelial glycosaminoglycans result in increased vascular permeability ${ }^{53}$ leading to the loss of intravascular fluid due to capillary leak and causes hypovolemia and shock. A subsequent loss of compensatory mechanisms leads to an impaired cardiac output. This leak occurs in all vascular beds. ${ }^{54}$ An increased loss of urinary albumin similar to that occurring in nephritic syndrome takes place, and this compounds the loss of fluid and electrolytes. ${ }^{55}$ The capillary leak also leads to accumulation of protein-rich fluids in the peritoneal and pleural spaces, and intra-alveolar spaces in the lung parenchyma thus leading to pulmonary edema and respiratory failure.

Vasoconstriction and vasodilatation: An important early protective mechanism to maintain tissue and organ perfusion in the face of diminished cardiac output is the onset of compensatory vasoconstriction. Patients with meningococcal sepsis initially have intense vasoconstriction clinically manifesting as cold peripheries and sluggish circulation to the tissues. This intense vasospasm may persist in some patients and lead to cold, pale, and ischemic limbs. Subsequently, thrombosis occurs within the microvasculature leading to gangrene. On the other hand, some patients have intense vasodilatation following resuscitation. These patients have bounding pulses and warm peripheries but severe hypotension and organ dysfunction (warm shock). Some patients may have a mix of both vasoconstriction and vasodilatation.

Loss of thromboresistance and intravascular coagulation: The normal vascular endothelium has a finely balanced interaction of procoagulant, antithrombotic, and thrombolytic pathways. In meningococcal sepsis, there is a disruption of this balance leading to the activation of procaogulant pathways and impairment of the natural anticoagulant pathways and fibrinolytic system. Procoagulant pathway upregulation leads to a generation of intravascular thrombin, which in turn binds to proteins $C$ and $S$ (main antithrombotic proteins) and thus affects all antithrombotic mechanisms. There is a decrease in the levels of prostacyclin and antithrombin production, decreased secretion of proteins $C$ and $\mathrm{S}$, increased plasminogen activator inhibitor-1 (PAI-1), and tissue factor expression. ${ }^{56}$ The levels of PAI- 1 increase to a great extent in meningococcal sepsis and have a direct correlation with the severity of the disease and death. ${ }^{5,57}$ High levels of PAl- 1 along with profound defects in antithrombotic mechanisms lead to widespread intravascular thrombosis. On the other hand, sluggish circulation due to impaired cardiac output leads to venous thrombosis. ${ }^{57}$

\section{Myocardial Dysfunction}

Myocardial dysfunction in meningococcal sepsis occurs secondary to negative inotropic effects of various proinflammatory cytokines such as nitric oxide, TNF- $\alpha$, and IL- $1 \beta .{ }^{58,59}$ Moreover, hypoxia, acidosis, hypoglycemia, hypokalemia, hypocalcaemia, and hypophophatemia, which are all common in meningococcal sepsis, adversely affect myocardial function. The levels of cardiac troponin 1 are increased in meningococcal septicemia and correlate with the severity of the disease. ${ }^{60}$

All the above four processes result in impairment of microvascular blood flow to the tissues and organs of the body leading to shock and multiorgan failure.

\section{Renal Impairment}

Some evidence of renal injury secondary to impaired renal perfusion related to the severity of shock is seen in most patients with meningococcal sepsis. Persistence of the decreased renal perfusion leads to oliguria and anuria with a rise in serum urea and creatinine. ${ }^{47}$ In a majority of patients, the renal impairment is transient and responds to fluid resuscitation but progression to vasomotor nephropathy and acute tubular necrosis is seen in a small group of severely affected patients. ${ }^{47}$

\section{Pulmonary Effects}

Capillary leak leads to early pulmonary involvement. This causes tachypnea, increased work of breathing, and ultimately progresses to hypoxic respiratory failure. Volume resuscitation and expansion of the circulating volume compound the problem by inducing more capillary leak, increased intra-alveolar fluid, and finally pulmonary edema and respiratory failure.

\section{Gastrointestinal Effects}

Most patients will have some gastrointestinal involvement secondary to shock with some having profound gastric ischemia, ileus, and occasional perforation. ${ }^{61}$

\section{Central Nervous System Effects in Meningococcal Septic Shock and Meningitis}

The effects on the central nervous system can be due to direct invasion of the meninges by the bacteria or secondary to shockinduced impaired organ perfusion. Most patients will have both. A significant proportion of patients with meningococcal meningitis develop raised intracranial tension secondary to the inflammatory process within the brain. Those who have profound shock invariably show diminished consciousness and are at risk of cerebral infarction if the circulation is not improved.

\section{Clinical Features}

Based on the pathophysiological events, patients with IMD can be classified into four groups: ${ }^{62}$

- Patients with bacteremia without shock

- Patients with bacteremia with shock but no meningitis

- Patients with bacteremia and meningitis, and

- Patients with meningitis alone.

A simpler classification is into three main groups-meningitis, meningococcemia, and meningitis with meningococcemia. Classifying patients into one of these clinically recognizable groups is helpful for clinical decision making like the initiation of immediate and maximal intensive care support.

Meningococci usually cause infection in children from 3 months to 5 years, and a second peak occurs in adolescents. ${ }^{63}$ The most common presentation is meningitis (30-60\%) due to the inherent and characteristic tropism of $N$. meningitidis toward the meninges. Characteristically, patients with meningococcal meningitis present with fever, severe headache, vomiting, neck stiffness with positive meningeal signs, photophobia, drowsiness, and confusion. It is not mandatory for meningococcal meningitis to be associated with rash. In our own experience from Meghalaya, rash was seen in only $24 \%$ of the cases. ${ }^{64}$ Seizures are present in $40 \%$ of cases. Young infants usually present with generalized symptoms such as fever, decreased activity, poor feeding, drowsiness, and seizures unlike older children and adolescents. Rash is seen very rarely in infants. ${ }^{63,65,66}$ Meningococcemia has a more abrupt presentation with fever, chills, nausea, vomiting, myalgias, and the classical purpuric or petechial rash with or without bullae formation. The absence of meningitis is a poor prognostic factor. Some studies have 

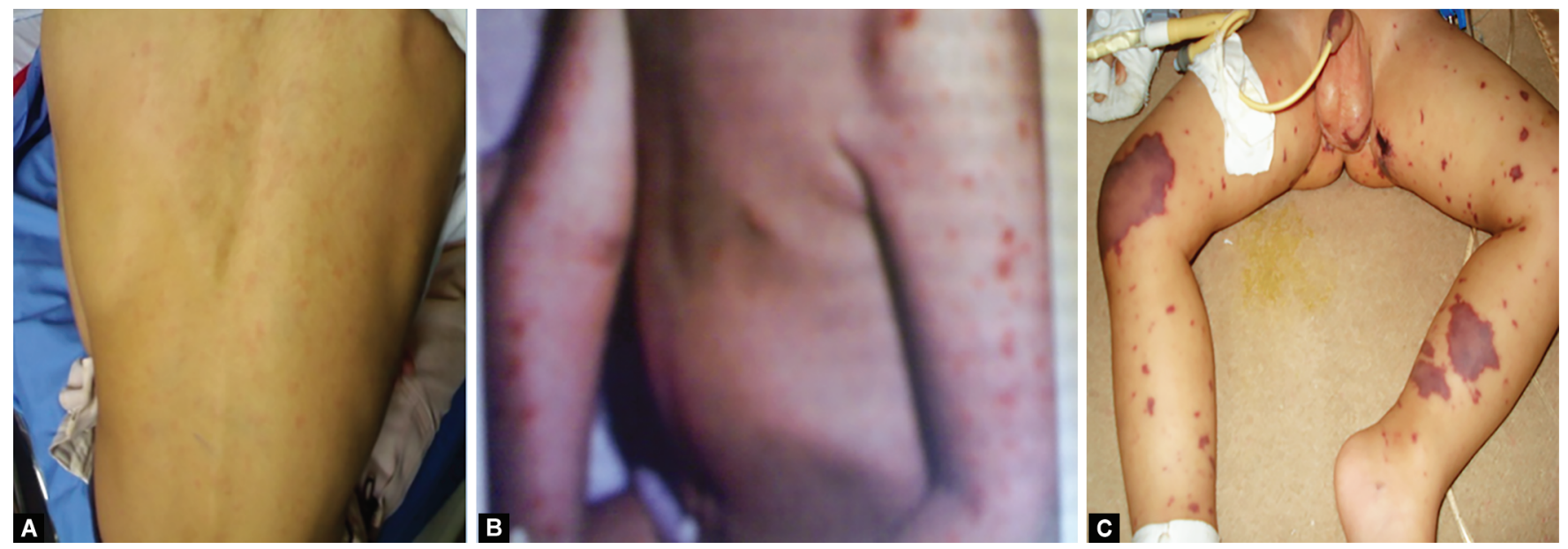

Figs 4A to C: Various forms of rashes seen in meningocococcal disease: (A) Faint rash; (B) Palpablepurpura; (C) Purpura fulminans

shown that children under 16 years frequently show the general symptoms of sepsis (leg pain, cold extremities, and abnormal skin color) in the first 12 hours of IMD (median onset 7-12 hours), particularly in severe meningococcemia, whereas the classic features like hemorrhagic rash, meningism, and impaired consciousness are late signs (median onset 13-22 hours). ${ }^{67}$ Some may present with chronic meningococcemia, and these patients usually have intermittent fever, rashes, arthritis, headaches, splenomegaly, endocarditis, and immune reactions. Meningococcal septicemia is primarily characterized by a classical purpuric rash in a patient who is febrile and tachycardic. The dictum is to always consider meningococcal septicemia in an unwell child with a purpuric rash unless proved otherwise. ${ }^{66,67}$ The purpuric rash may vary widely in patients with some having faint rashes to more prominent ones known as purpura fulminans (Fig. 4).

The standard case definition of meningococcal meningitis and meningococcemia is as follows (2015 Centres for Disease Control and Prevention (CDC) case definitions) ${ }^{68}$

\section{SUSPECT}

- Clinical purpura fulminans in the absence of a positive blood culture, or

- Gram-negative diplococcic, not yet identified, isolated from a normally sterile site (e.g., blood or CSF)

\section{Probable}

- Detection of N. meningitidis-specific nucleic acid in a specimen obtained from a normally sterile body site (e.g., blood or CSF), using a validated polymerase chain reaction (PCR) or

- Detection of $N$. meningitidis antigen:

- In formalin-fixed tissue by immunohistochemistry (IHC) or

- In CSF by latex agglutination.

\section{Confirmed}

- Detection of N. meningitidis-specific nucleic acid in a specimen from a normally sterile body site (e.g., blood or CSF) using a validated PCR assay or

- Isolation of $N$. meningitidis:

- from a normally sterile body site (e.g., blood or CSF, or less commonly, synovial, pleural, or pericardial fluid) or

- from purpuric lesions.
Severe meningococcal disease progresses rapidly to shock, multiple organ failure and death within 24 hours. In our own experience, very sick patients died within a few hours of hospital admission. ${ }^{64}$ The first $4-6$ hours patients have nonspecific symptoms such as fever, drowsiness, nausea, and poor feeding. In the next 12 hours, nonspecific signs of sepsis such as leg pain, cold hands and feet, and abnormal color appear. The classical rapidly evolving purpuric rash, neck pain, and stiffness usually develop after 12 hours. ${ }^{69}$ Unfortunately, most of the cases of meningococcal disease are diagnosed after the appearance of the late signs, and it is not infrequent for children who are admitted to hospital to have been initially misdiagnosed. Literature promotes the "tumbler test" (pressing a transparent tumbler or glass on the rash for a few seconds) to parents as a way of confirming the nonblanching nature of the rash. ${ }^{70}$ If the non-blanching rash is purpuric (more than $2 \mathrm{~mm}$ in diameter) in an ill febrile child, then meningococcal disease is very likely. About $11 \%$ of children with an exclusively petechial rash will have a meningococcal disease. ${ }^{71}$ Most others will have viral infections. Up to $30 \%$ of children with meningococcal disease may present with a nonspecific maculopapular rash. ${ }^{72}$

\section{Management}

Urgent and aggressive management is the key to management of this potentially fatal disease. The treatment receives priority over investigations. Studies have shown that early institution of parenteral antibiotic significantly reduces mortality. No differentiation between meningococcemia and meningitis should be made during management as consideration of cases as only meningitis leads to a failure of anticipation of the development of shock and its timely management. ${ }^{68}$ Rapid progression can occur even after admission. ${ }^{73}$

The initial management consists of a quick goal-directed assessment followed by securing the airway and addition of supplemental oxygen and supported by ventilation wherever the need arises. Parenteral antibiotic should be given as soon as possible, and especially if one needs to transport the patient, the emergency team should give the first dose of antibiotic while the patient is being transported. Treatment receives priority over investigations as the primary aim is to achieve a reduced "door to needle time" (i.e., the time between the first arrival at a health facility and the first dose of antibiotic), which has been seen to influence 
the prognosis. ${ }^{74}$ During management in the hospital, one must anticipate the development of shock, vomiting, and respiratory failure. Some important early interventions are comprised of insertion of a nasogastric tube, early intubation, and ventilation with $100 \%$ oxygen without waiting for respiratory failure to develop especially in patients with septicemia.

\section{Critical Points in Management of Meningococcal Disease}

\section{Shock}

Shock in meningococcemia is of multifactorial origin-widespread capillary leak, loss of vasomotor tone, maldistribution of intravascular volume, impaired myocardial function, and impaired cellular function. An early recognition of shock is crucial as it leads to early intervention and improved outcome. ${ }^{74}$ Tachycardia may be the only early sign present in the early phase of the disease and should be enough to mandate fluid resuscitation. The goal of circulatory management is to maintain tissue perfusion and oxygenation. An intraosseous line is inserted in case of failure of intravenous access in the first 90 seconds. Repeated fluid boluses comprising 20 $\mathrm{mL} / \mathrm{kg}$ of isotonic saline are given initially till shock resolves. In case shock persists after $60 \mathrm{~mL} / \mathrm{kg}$ of fluid, then further fluids increase the risk of pulmonary edema and such patients need transfer to a tertiary center for elective intubation, mechanical ventilation, and insertion of a central venous pressure (CVP) line. Fluid resuscitation is then continued followed by addition of dopamine and/or dobutamine on the basis of volume status assessments by using the blood pressure, pulse volume, capillary refill time, and CVP measurements. Many children with meningococcal disease may require as high as $100-200 \mathrm{~mL} / \mathrm{kg}$ of fluid resuscitation but such patients also require mechanical ventilation. In our own experience, we had to use normal saline from 20 to $200 \mathrm{~mL} / \mathrm{kg} .{ }^{64}$ Some studies have shown that $4.5 \%$ albumin is more useful as a resuscitating fluid. ${ }^{73}$ The children with meningococcal disease are known to present with severe sepsis and lower serum albumin levels and may therefore benefit from $5 \%$ albumin. Albumin is routinely used by many pediatric intensivists in the UK, and over the last 20 years, there has been a significant reduction in the mortality (decreased up to $2 \%$ ) in patients with meningococcal disease; the routine use of albumin may play a role along with other factors. ${ }^{74}$ The National Institute for Health and Clinical Excellence (NICE), U.K., guidelines ${ }^{75}$ recommends using $20 \mathrm{~mL} / \mathrm{kg}$ of isotonic saline or $4.5 \%$ albumin solution for the subsequent boluses. However, in our experience we have used only normal saline or Ringer's lactate as a resuscitating fluid and not albumin. Shock must be treated aggressively. Persistent shock has an adverse impact on survival in a time-dependent manner with at least a two-fold increase in mortality for every hour of delay in treatment. ${ }^{70}$ When shock is reversed within 75 minutes of presentation, there is a $94 \%$ rate of survival. ${ }^{74}$ If a child presents with signs of shock and hepatosplenomegaly or rales, it may indicate coexistent myocardial dysfunction, and fluid resuscitation must be done with extreme care and caution. Maintenance fluids are given with a careful assessment of intravascular status. There is no role of fluid restriction unless there is evidence of raised intracranial pressure (ICP) or syndrome of inappropriate antidiuretic hormone secretion (SIADH). ${ }^{75}$ Patients may present with generalized anasarca due to a capillary leak or SIADH (Fig. 5).

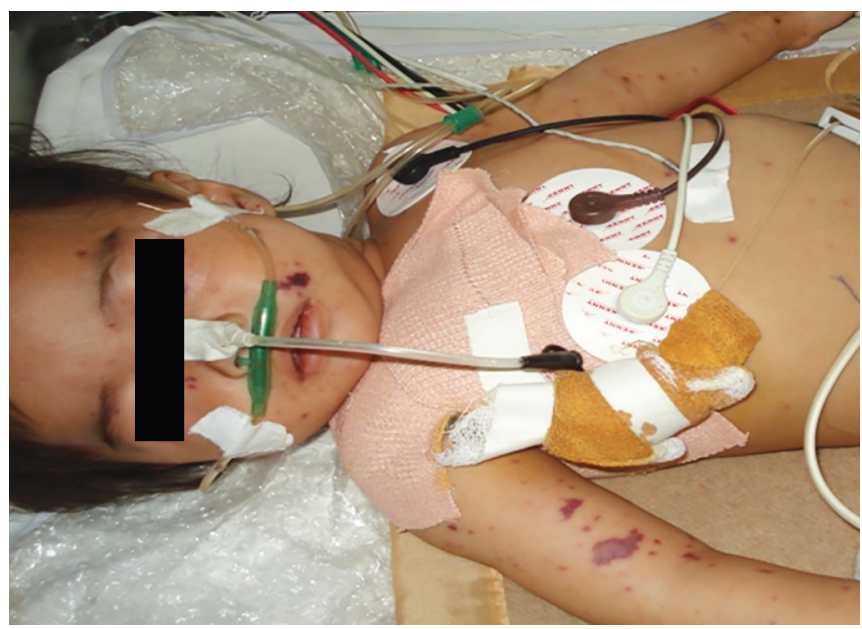

Fig. 5: Periorbital swelling in a patient with meningococcemia (secondary to capillary leak)

\section{Hemodynamic Support}

The first-line treatment of hemodynamic disorder in meningococcal disease is with fluids. If the child remains unstable even after adequate fluid resuscitation, then vasoactive drugs are needed. The first-line vasopressor is noradrenaline for the treatment of hypotension infused via a central line. In the absence of noradrenaline, dopamine can be given. In case of associated myocardial dysfunction, dobutamine is to be used. In our experience, we have used mostly dopamine and dobutamine as vasopressors with good response.

\section{Intubation and Mechanical Ventilation}

It is mandatory to ventilate patients with shock not only to avoid risk of pulmonary edema but also to reduce the work of breathing and oxygen consumption. The NICE guidelines recommend elective intubation and mechanical ventilation with vasoactive drugs once $60 \mathrm{~mL} / \mathrm{kg}$ of fluids are required for volume resuscitation. ${ }^{75}$ A low Glasgow coma scale (GCS) $(<8)$, hypoxia, respiratory failure, pulmonary edema and raised ICP are also other indications for elective intubation. Rapid sequence intubation is the preferred method. However, shock should be corrected before intubation as induction anesthesia may exacerbate the shock. If there is no evidence of raised ICP, then ketamine may be used because of its ability to have a positive effect on the hemodynamic status along with atropine to circumvent reflex bradycardia, which may worsen shock. Intubation must be performed by a professional with good experience in pediatric airway management.

\section{Choice of Antibiotic}

The cornerstone of therapy in meningococcal disease is appropriate antibiotics. The factors that influence the success of antibiotic therapy are the timing of the antibiotic, the ability of the antibiotic to penetrate the tissues, and the presence of antibiotic resistance. Broad spectrum antibiotics should be used. The most widely used antibiotics in the world are Penicillin G, ceftriaxone, and cefotaxime. Increasing reports of reduced susceptibility of $N$. meningitidis to Penicillin has come from various parts of the world, ${ }^{76,77}$ and therefore, the recommended first-line therapy in the present scenario is ceftriaxone. In 2010, in Latin America, of the 506 strains 
of $N$. meningitidis tested for antibiotic susceptibility, $87 \%$ were susceptible to Penicillin and $13 \%$ had intermediate susceptibility. None of the strains were resistant. All the strains were also sensitive to chloramphenicol. ${ }^{66}$ However, in our experience we had patients with good response to ceftriaxone only in the beginning of the epidemic. After about 6 months of the epidemic, there was a poor clinical response to ceftriaxone and antibiotic policy in our unit was revised to intravenous chloramphenicol for 7 days with a good response. ${ }^{64}$ There are other reports of ciprofloxacin and ceftriaxone resistance from India. ${ }^{78,79}$ The second-line therapy consists of vancomycin and azithromycin. Though there are no studies to demonstrate the adequate duration of antibiotic therapy for N. meningitidis, classically a 7-day course of antibiotic is followed. ${ }^{80,81}$

\section{Correction of Metabolic Abnormalities}

Metabolic abnormalities such as metabolic acidosis, hypokelemia, hypocalcemia, hypomagnesemia, hypophosphatemia, hyponatremia, and hypernatremia are common and require management accordingly. Hyponatremia is usually caused by SIADH, cerebral salt wasting or adrenal insufficiency due to Waterhouse-Friderichsen syndrome. Magnesium replacement is required in cases of persistent hypokelemia. Bicarbonate infusions are indicated if the $\mathrm{pH}$ is less than 7.2. In our experience, there have been a significant number of patients who have progressed rapidly to develop diabetes insipidus (DI), which required an aggressive management with hypotonic fluids and vasopressin. All our patients with DI had $100 \%$ mortality. ${ }^{64}$ Hyperglycemia secondary to stress, peripheral resistance to insulin, and allied anabolism is quite common. In children with meningococcal disease, a small cohort of patients showed an association between hyperglycemia and severity of disease. In these patients, hyperglycemia was associated with low levels of insulin in contrast to findings in adults. ${ }^{82}$ Severe hyperglycemia (blood glucose $>200 \mathrm{mg} / \mathrm{dL}$ ) should be treated with insulin.

\section{Raised ICP}

Small proportion of patients present with raised ICP. In those with raised ICP, there is a decreased cerebral blood flow due to hypotension or raised ICP itself. Raised ICP is managed with mannitol, $3 \%$ saline, controlled mechanical ventilation aiming at a $\mathrm{pCO}_{2}$ of $30-35 \mathrm{~mm} \mathrm{Hg}$, and sedation if required. In case of coexistence of shock with raised ICP, the management of shock takes precedence over raised ICP. The best therapy for the control of raised ICP is adequate control of blood pressure. Cannulation of the internal jugular vein must be avoided in patients with raised ICP. In patients with raised ICP (reduced or fluctuating level of consciousness, i.e., GCS of $<9$ or a drop of 3 or more), relative bradycardia and hypertension, focal neurological signs, abnormal posture, or posturing, unequal, dilated, or poorly responsive pupils, papilledema, abnormal "doll's eye" movements, shock, extensive, or spreading purpura, recent convulsions and child yet to be stabilized, coagulation abnormalities, local infection at the LP site, and cardiorespiratory insufficiency, the lumbar puncture must be deferred. ${ }^{75}$ In fact, it is recommended that antimeningitic doses of antibiotic must be initiated without waiting for a LP. ${ }^{65}$ All patients with a GCS of $\leq 9$ must be admitted in a pediatric intensive care unit.

\section{Seizures}

Seizures may be the first manifestation of meningitis. Treatment comprises airway protection, ensuring adequacy of breathing, and circulation and measurement of blood glucose and electrolytes.
The seizures are treated with benzodiazepines, phenytoin, or phenobarbitone. Such patients would require monitoring for respiratory depression and need for elective intubation and mechanical ventilation especially in those with status epilepticus.

\section{Steroids}

The NICE guidelines recommend the following as far as steroids use are concerned in meningococcal meningitis: ${ }^{75}$

- Steroids are contraindicated in children younger than 3 months of age who have suspected or confirmed bacterial meningitis.

- Dexamethasone at $0.15 \mathrm{mg} / \mathrm{kg}$ per dose to a maximum of $10 \mathrm{mg}$, four times a day for 4 days for suspected or confirmed bacterial meningitis as soon as possible if lumbar puncture shows any of the following: frankly purulent CSF, CSF with white blood cell (WBC) count $>1,000 / \mathrm{mm}^{3}$, increased CSF WBC count with protein concentration $>1 \mathrm{~g} / \mathrm{L}$, bacteria on gram stain.

Other studies have also recommended the routine use of dexamethasone in meningococcal meningitis as it is not associated with any adverse outcome and in fact decreases the incidence of arthritis. ${ }^{66}$ This is said to reduce neuronal damage if given prior to the first dose of antibiotic. Steroids are not indicated in meningococcal shock unless there is suspicion of hypoadrenalism in which case hydrocortisone at a dose of $1 \mathrm{mg} / \mathrm{kg}$ is given six hourly.

\section{Coagulation Disorders}

Coagulopathy is frequent and multifactorial. Shock induces endothelial damage, vasculitis, and disseminated intravascular coagulation (DIC). No effective therapies for coagulation disorders associated with meningococcal disease exist. Mild clotting abnormalities may not be treated as they are well tolerated. Fresh frozen plasma (FFP) is recommended in severe coagulopathy. In our experience, we have used intravenous vitamin $\mathrm{K}$ and if required FFP with good results. ${ }^{64}$ Currently, the best treatment for meningococcal-related coagulopathy is the optimal management of shock.

\section{Limb Ischemia/Perfusion}

Necrotic areas can consume clotting factors and worsen coagulopathy. These areas also serve as reservoir for bacteria. Necrotic areas must be monitored carefully and surgical debridement must be done if extensive. The use of hyperbaric oxygen has been reported for the management of such necrotic tissues. ${ }^{83}$

\section{Arthritis}

Arthritis may occur early in the disease due to direct bacterial seeding of the joints. However, arthritis may be seen in the subacute or convalescent phase of the illness due to immune-complex reactions. The treatment of the bacterial arthritis consists of antibiotics and drainage of joint fluid if needed. Immune complex reactions are usually treated with nonsteroidal anti-inflammatory drugs or steroids. In our experience, we had one such patient with immunecomplex-mediated arthritis in whom we had to use intravenous immunoglobulin as a last resort and with excellent response. ${ }^{84}$

\section{Prognostication in Meningococcal Disease}

Meningococcal disease remains a challenge because of its potential fulminant behavior. To meet the need for a rapid clinical-based 
Table 1: Stiehm and Damrosch criteria

- Petechiae present for $<12$ hours before admission

- Hypotension (systolic blood pressure $<70 \mathrm{~mm} \mathrm{Hg}$ )

- Absence of meningitis ( $<20 \mathrm{WBC}$ in CSF)

- Peripheral white cell count $<10,000 / \mathrm{mm}^{3}$

- $\mathrm{ESR}<10 \mathrm{~mm} / \mathrm{hour}$

When three or more factors were present, mortality was $90 \%$, and when two or less factors were present, mortality was $9 \%{ }^{85}$

Table 2: Glasgow meningococcal septicaemia prognostic score (GMSPS) ${ }^{86}$

\begin{tabular}{lll}
\hline S.no. & Criteria & Score \\
\hline 1 & Hypotension* & 3 \\
2 & Skin/rectal temperature difference $>3^{\circ} \mathrm{C}$ & 3 \\
3 & Base deficit (capillary sample) $<8 \mathrm{mmol} / \mathrm{L}$ & 1 \\
4 & $\begin{array}{l}\text { Modified pediatric coma score }<8 \text { anytime or } \\
\text { deterioration of } 3 \geq \text { in an hour }\end{array}$ & 3 \\
5 & $\begin{array}{l}\text { Lack of meningitis } \\
6\end{array}$ & $\begin{array}{l}\text { Parental opinion that the child's condition has } \\
\text { worsen over the past hour }\end{array}$ \\
7 & $\begin{array}{l}\text { Widespread ecchymoses or extending lesions on } \\
\text { review }\end{array}$ & 1 \\
\hline
\end{tabular}

*Systolic BP $<75 \mathrm{~mm} \mathrm{Hg}$ if below 4 years of age, $<85 \mathrm{~mm} \mathrm{Hg}$ if older Note: Any score $>8$ out of 15 in the GMSPS and the presence of three or more factors in the Stiehm and Damrosch systems have a fatal outcome

assessment, several prognostic scoring systems have been devised. Among these, the most popular are the Stiehm and Damrosch (Table 1) and the Glasgow meningococcal septicemia prognostic score (GMSPS) (Table 2). ${ }^{85,86}$ Case fatality in IMD is about $10 \%$. Despite advanced intensive care management, case fatality from fulminant meningococcal disease still remains at about $50-60 \%$ and most commonly occurs from cardiac or respiratory failure. ${ }^{87}$

\section{Care for Relatives and Care Givers}

The occurrence of meningococcal disease in household contacts is 100 -fold higher than in the normal population. ${ }^{81}$ So, all close contacts require chemoprophylaxis. Close contacts include household members, child-care center contacts, and anyone directly exposed to the patient's oral secretions in the 7 days preceding symptoms. Rate of secondary disease is most after the onset of disease in the index patient. Therefore, antimicrobial chemoprophylaxis should be administered ideally within 24 hours of the identification of the index patient. ${ }^{88}$ The drugs used for chemoprophylaxis are ciprofloxacin, ofloxacin, rifampicin, azithromycin, and ceftriaxone as per the doses mentioned in Table 3. ${ }^{29,89}$

\section{Vaccination and Prevention of IMD}

The epidemiology of meningococcal disease is such that in most places, the infection continues to simmer for 10 years or so with the propensity to cause intermittent epidemics. So, immunization forms an important way to prevent the disease. All close contacts and healthcare workers managing the cases in the wards, and microbiologists should be routinely vaccinated against the disease.

The vaccines that were available were the polysaccharide bivalent $A-C$ vaccine, trivalent ACW135 and tetravalent ACYW135. Subsequently, better conjugate meningococcal vaccines have become available worldwide. The conjugation is done with diphtheria
Table 3: Drugs for chemoprophylaxis against meningococcal disease ${ }^{89}$

Ciprofloxacin

Adults and children over $\quad 500 \mathrm{mg} \quad$ Single dose $\quad \mathrm{PO}$

12 years

Children aged $5-12$ years $250 \mathrm{mg}$ Single dose PO

Children aged 1 month-4 $125 \mathrm{mg} \quad$ Single dose PO

years

Alternative regimens

Rifampicin

Adults and children over

12 years

Children aged $1-12$ years

$600 \mathrm{mg}$

$\mathrm{BD}$

$10 \mathrm{mg} /$

$\mathrm{BD}$

$\mathrm{kg}(\max$

$600 \mathrm{mg})$

Neonates and infants

$5 \mathrm{mg} / \mathrm{kg} \quad$ BD

under 1 year

Prophylaxis of meningococcal meningitis in pregnant contact

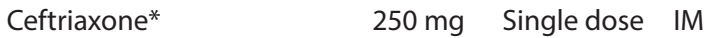

Ofloxacin

$400 \mathrm{mg}$ Single dose Oral

*Not licensed for this indication; therefore, counseling should be given

toxin (DT), CRM 197, and tetanus toxoid (TT). The conjugate vaccines currently used are the monovalent Men A TT (Men Afri A), monovalent Men $B$ vaccine (available as Trumenda and Bexsero), HibMen $C$ (conjugated with TT), and tetravalent conjugate Men ACWY vaccines conjugated with CRM 197 (Menveo), TT (Nimenrix), or DT (Menactra). Currently, Serum Institute of India is working on producing a pentavalent thermostable meningococcal vaccine (ACYW135X).

Different countries have different recommendations for vaccination based on the prevalent epidemiology in the region. In most European countries, the United States, Australia, and New Zealand, infants would receive $2-3$ doses of Men B starting at 6-8 weeks of life followed by two doses of Men ACWY between 9 months and 23 months of age and a booster at 11-16 years of age. Men $B$ is also recommended for children above 10 years or older if they live in the areas with high risk of Men B disease, those with asplenia or have undergone a splenectomy, persistent complement deficiency, on immunosuppresants or are exposed to the bacteria in the microbiology laboratories. The Advisory Committee on Immunization Practices of the CDC recommends that the quadrivalent meningococcal conjugate vaccine (ACWY) be given to all children between 11 years and 18 years of age, and to those between 2 years and 55 years of age who are at increased risk of meningococcal disease, i.e., those with increased susceptibility such as persistent complement component deficiencies (C3, properdin, factor $D$, and late complement deficiencies), persons with anatomic or functional asplenia, those who have prolonged exposure (e.g. microbiologists routinely working with $N$. meningitidis, or travelers to, or residents of countries where meningococcal disease is hyperendemic or epidemic), persons with HIV, and first-year college students in resident halls. ${ }^{90}$ Vaccine is also recommended for outbreak control. In India, the Indian Academy of Pediatrics recommends the Men ACWY from 9 months to 23 months ( 2 doses 3 months apart), and in 2-50 years for high-risk groups. ${ }^{91}$ As per $\mathrm{NCDC}$, meningococcal vaccines in India are recommended for $\mathrm{Haj}$ pilgrims and other travelers visiting countries where meningococcal disease is a major problem or where frequent outbreaks occur, highrisk group like children in orphanages, jail inmates, and soldiers in barracks, and in mass vaccination during epidemics. ${ }^{29}$ 


\section{Key Learning Points}

- Meningococcal disease is potentially fatal with high mortality.

- It is one of the emerging infectious diseases with new areas being affected. Epidemics continue to occur with mostly serogroups $A, C, Y$, and $W-135$. Serogroup $B$ is more common in the developed countries and in infants.

- The organism has great capacity to adhere to human epithelial cells and internalize by various mechanisms inherent to its structure and composition.

- Clinical effects are dramatic and may be in the form of septicemia, meningitis, or both. Almost all organ systems are affected.

- Early and aggressive therapy improves survival dramatically.

- Prognosis is greatly affected by a reduced "house-to-hospital" and "door-to-needle" time.

- Awareness is required for a prompt recognition and early referral and aggressive management. The role of the general practitioners therefore assumes utmost importance as they can reduce mortality by early interventions and early referral.

- The management of cases in an intensive care setup improves survival, and all patients even if not sick at admission must be kept under intensive care and monitoring.

- Chemoprophylaxis of close contacts and vaccination of high-risk groups are mandatory.

- The conjugate quadrivalent (ACWY) and an effective serogroup $B$ vaccine are now available.

\section{References}

1. Jafri RZ, Ali A, Messonnier NE, et al. Global epidemiology of invasive meningococcal disease. Popul Health Metr 2013;11(1):17. DOI: 10.1186/1478-7954-11-17.

2. Vieusseux M. Mémoire sur la maladie qui a regné a Genêve au printemps de 1805. J Med Chir Pharmacol 1805;11:163-163.

3. Marchiafava E, Celli A.Soprai micrococchi della meningite cerebrospinale epidemica. Gazz degli Ospedali 1884;5:59 [Italian]. [Google Scholar].

4. Flexner $\mathrm{S}$. The results of serum treatment in thirteen hundred cases of epidemic meningitis. J Exp Med 1913;17(5):553-576. DOI: 10.1084/ jem.17.5.553.

5. Neisseria DankertJ. Text book of infectious disease. Cohen J and Powderly, 2nd ed., vol. 2 Philadelphia: Mosby; 2004. pp. 2173-2187.

6. Manchanda V, Gupta S, Bhalla P. Meningococcal disease: History, epidemiology, pathogenesis, clinical manifestations, diagnosis, antimicrobial susceptibility and prevention. IJMM 2006;24(1):7-19. DOI: 10.4103/0255-0857.19888.

7. Frash CE, Zollinger WD, Poolman JT. Serotype antigens of Neisseria meningitidis and a proposed scheme for designation of serotypes. Rev Infect Dis 1985;7(4):504-510. DOI: 10.1093/clinids/7.4.504.

8. Vogel U, Claus H, Frosch M. Rapid serogroup switching in Neisseria. N Engl J Med 2000;324(3):219-220. DOI: 10.1056/ NEJM200001203420319.

9. Swartley JS, Marfin AA, Edupuinganti S, et al. Capsule switching of Neisseria meningitidis. Proc Natl Acad Sci USA 1997;94(1):271-276. DOI: 10.1073/pnas.94.1.271.

10. Virji M, Saunders JR, Sims G, et al. Pilus-facilitated adherence of Neisseria meningitidis to human epithelial and endothelial cells: Modulation of adherence phenotype occurs concurrently with changes in primary aminoacid sequences and the glycosylation of pilin. Mol Microbiol 1993;10(5):1013-1028. DOI: 10.1111/j.13652958.1993.tb00972.x.

11. Heckels JE. Structure and function of pili of pathogenic Neisseria species. Clin Microbiol Rev 1989;2(Suppl):66-73. DOI: 10.1128/ CMR.2.Suppl.S66-S73.1989.
12. Meyer TF, Pohlner J, Van Putten JPM. Biology of pathogenic Neisseria. Curr Top Microbiol Immune 1994;192:283-317.

13. Hitchcock PJ. Unified nomenclature for pathogenic Neisseria species. Clin Microbiol Rev 1989;2(Suppl):64-65. DOI: 10.1128/CMR.2.Suppl. S64-S65.1989.

14. Virji $M$, Evans $D$, Hadfield S, et al. Critical determinants of host receptor targeting by Neisseria meningitidis and Neisseria gonorrhoeae: Identification of Opa adhesitopes on the N-domain of CD66 molecules. Mol Microbiol 1999;34(3):538-551. DOI: 10.1046/j.13652958.1999.01620.x.

15. De Vries FP, Cole R, Dankert J, et al. Neisseria meningitis producing Opc afhesion binds epithelial cell proteoglycan receptors. Mol Microbiol 1998;27(6):1203-1212. DOI: 10.1046/j.1365-2958.1998.00763.x.

16. Swanson J, Bellard RJ, Hill SA. Neisserial surface variation: how and why? Curr Opin Genet Dev 1992;2(5):805-811. DOI: 10.1016/S0959437X(05)80143-1.

17. Brandtzaeg P. Systemic meningococcal disease: clinical pictures and patho-physiological background. Rev Med microbial 1996;7:63-72. DOI: 10.1097/00013542-199604000-00001.

18. Harrison $\mathrm{OB}$, Claus $\mathrm{H}$, Jiang $\mathrm{Y}$, et al. Description and nomenclature of Neisseria meningitides capsule locus. Emerging Infectious Disease 2013;19:4. DOI: 10.3201/eid1904.111799.

19. Das BK, Agrawal SK. Meningococcal meningitis in northern indiastudy of an endemic disease. TB of meningococcal meningitis - Recent perspective, ch. 2, Chaudhry Rama, Kotentwork; 2019. pp. 6-20. ISBN: 978-93-83988-13-6.

20. Schwartz B, Moore PS, Broome CV. Global epidemiology of meningococcal disease. Clin Microbiol Rev 1989;2(Suppl 2):S118-S124. DOI: 10.1128/CMR.2.Suppl.S118-S124.1989.

21. Brouwer MC, Tunkel AR, Van de Beek D. Epidemiology, diagnosis and antimicrobial treatment of acute bacterial meningitis. Clin Microbiol Review 2010;23(3):467-492. DOI: 10.1128/CMR.00070-09.

22. Steinhoff MC. Global epidemiology of meningococcal infections. TB of Infectious Disease Epidemiology - Theory and practice Nelson KE, Williams CM 2nd ed., Sudbury, Massachussets: Jones and Bartlett; 2007. pp. 637-651.

23. Meningoccal in meningitis - Australian meningococcal surveillance program.

24. Lingappa JR, Al-Rabeah AM, Hajjeh R, et al. Serogroup W-135 meningococcal disease during the hajj, 2000. Emerg Infect Dis 2003;9:665-671. DOI: 10.3201/eid0906.020565.

25. Greenwood B. 100 Years of epidemic meningitis in west Africa- Has anything changed? Trop Med Int Health 2006;11(6):773-780. DOI: 10.1111/j.1365-3156.2006.01639.x.

26. Lepeyssonnie L. La méningite cérébrospinalé en Afrique. Bull WHO 1963;28(Suppl):53-114.

27. Hazarika RD. Response to epidemic meningitis in Africa, 1997. Wkly Epidemiol Rec 1997;72(42):313-318.

28. Health Status Indicators, National Health Profile, 2018, Government of India, cbhidghs.nic.in.

29. Meningococcal disease: Need to remian alert. CD Alert. Monthly newsletter of teh National Centre for Disease Control, Directorate General of Health Services, Government of India, Oct-Nov 2009; Vol. 13: No. 3.

30. Orr HJ, Gray SJ, Macdonald M, et al. Saliva and meningococcal transmission. Emerg Infect Dis 2003;9(10):1314-1315. DOI: 10.3201/ eid0910.030344.

31. Nelson JD. Jails, microbes, and the three-foot barrier. NEJM 1996;335(12):885-886. DOI: 10.1056/NEJM199609193351210.

32. Caugant DA, Hoiby EA, Rosenqvist E, et al. Transmission of Neisseria meningitidis among asymptomatic military recruits and antibody analysis. Epidemiol Infct 1992;109(2):241-253. DOI: 10.1017/ S0950268800050196.

33. van Deuren $M$, Brandtzaeg $P$, van der Meer JWM. Update on meningococcal disease with emphasis on pathogenesis and clinical 
management. Clin Microbiol Rev 2000;13(1):144-166. DOI: 10.1128/ CMR.13.1.144.

34. Stephens DS, Farley MM. Pathogenic events during infection of the human nasopharynx with Neisseria meningitis and Haemophilus influenzae. Rev Infec Dis 1991;13(1):22-23. DOI: 10.1093/clinids/13.1.22.

35. Hill DJ, Griffiths NJ, Borodina E, et al. Cellular and molecular biology of Neisseria meningitis colonization and invasive disease. Clin Sci 2010;118:547-564. DOI: 10.1042/CS20090513.

36. Feavers IM, Pizza M. Meningococcal protein antigens and vaccines. Vaccine 2009;27(Suppl 2):B42-B50.DOI: 10.1016/j.vaccine.2009.05.001.

37. Merz AJ, So M, Sheetz MP. Pilus retraction powers bacterial twitching motility. Nature 2000;407(6800):98-102. DOI: 10.1038/35024105.

38. Marceau M, Forest $\mathrm{K}$, Beretti JL, et al. Consequences of the loss of O-linked glycosylation of meningococcal type IV pilin on piliation and pilus-mediated adhesion. Mol Microbiol 1998;27(4):705-715. DOI: 10.1046/j.1365-2958.1998.00706.x.

39. Diaz Romero J, Outschoorn IM. Current status of meningococcal group B vaccine candidates: capular or noncapsular? Clin microbial rev 1994;7(4):559-575. DOI: 10.1128/CMR.7.4.559-575.1994.

40. Leimkugel J, Hodgson A, Forgor AA, et al. Clonal waves of Neisseria colonisation and disease in the african meningitis belt: eight-year longitudinal study in northern Ghana. PLoS Med 2007;4(3):e101. DOI: 10.1371/journal.pmed.0040101.

41. Mairey E, Genovesio A, Donnadieu E, et al. Cerebral microcirculation shear stress levels determine Neisseria meningitidis attachment sites along the blood-brain barrier. J Exp Med 2006;203(8):1939-1950. DOI: 10.1084/jem.20060482.

42. Mikaty G, Soyer M, Mairey E, et al. Extracellular bacterial pathogen induces host cell surface reorganization to resist shear stress. PLoS Pathog 2009;5(2):e1000314. DOI: 10.1371/journal.ppat.1000314.

43. Carbonnelle $E$, Hill DJ, Morand $P$, et al. Meningococcal interactions with the host. Vaccine 2009;27(Suppl 2):B78-B89. DOI: 10.1016/j. vaccine.2009.04.069.

44. Uria MJ, Zhang Q, Li Y, et al. A generic mechanism in Neisseria meningitidis for enhanced resistance against bactericidal antibodies. J Exp Med 2008;205(6):1423-1434. DOI: 10.1084/jem.20072577.

45. Nassif X, Pujol C, Morand P, et al. Interactions of pathogenic Neisseria with host cells. Is it possible to assemble the puzzle? Mol Microbiol 1999;32(6):1124-1132. DOI: 10.1046/j.1365-2958.1999.01416.x.

46. Massari $P$, Ho $Y$, Wetzler LM. Neisseria meningitidis porin Por $b$ interacts with mitochondria and protects cells from apoptosis. Proc Natl Acad Sci USA 2000;97(16):9070-9075. DOI: 10.1073/ pnas.97.16.9070.

47. Sullivan TD, LaScolea LJ Jr. Neisseria meningitidis bacteremia in children: quantification of bacteremia and spontaneous clinical recovery without antibiotic therapy. Pediatrics 1987;80(1):63-67.

48. Pathan N, Faust SN, Levin M. Pathophysiology of meningococcal meningitis and septicaemia. Arch Dis Child 2003;88(7):601-607. DOI: 10.1136/adc.88.7.601

49. Brandtzaeg $P$, Kierulf $P$, Gaustad $P$, et al. Plasma endotoxin as a predictor of multiple organ failure and death in systemic meningococcal disease. J Infect Dis 1989;159(2):195-204. DOI: 10.1093/infdis/159.2.195.

50. Anderson BM. Endotoxin release from Neisseria meningitidis. Relationship between key bacterial characteristics and meningococcal disease. Scand J Infect Dis 1989;64:1-43. DOI: 10.3109/inf.1989.21. suppl-64.01.

51. Prins JMP, Lauw FN, Derkx BHF, et al. Endotoxin release and cytokine production in acute and chronic meningococcemia. Clin Exp Immunol 1998;114(2):215-219. DOI: 10.1046/j.1365-2249.1998.00715.x.

52. Lewis LA, Sanjay R. Meningococcal disease and the complement system. Virulence 2014;5(1):1-29. DOI: 10.4161/viru.26515. www. landesbioscience.com

53. Wright SD, Ramos RA, Tobias PS, et al. CD14, a receptor for complexes of lipoppolysaccharide (LPS) and LPS binding protein. Science 1990;249(4975):1431-1433. DOI: 10.1126/science.1698311.

54. Klein NJ, Shennan Gl, Heydermann RS, et al. Alteration in glycosaminoglycan metabolism and surface change on human umbilical vein endothelial cells induced b cytokines, endotoxin and neutrophils. J Cell Sci 1992;102(Pt. 4):821-832.

55. Oragui $E E$, Nadel $S$, Kyd $P$, et al. Increased excretion of urinary glycosaminoglycans in meningococcal septicaemia and their relationship to proteinuria. Crit Care Med 2000;28(8):3002-3008. DOI: 10.1097/00003246-200008000-00054.

56. Kornelisse Rf, Hazelzet JA, Salvelkoul HF, et al. The relationship between plasminogen activator inhibitor-1 and proinflammatory and counterinflammatory mediators in children with meningococcal septic shock. J Infect Dis 1996;173(5):1148-1156. DOI: 10.1093/ infdis/173.5.1148.

57. Hermans PW, Hibberd ML, Booy $R$, et al. 4G/5G promoter polymorphism in the plasminogen activator inhibitor-1 gene and outcome of meningococcal disease. Meningococcal research group. Lancet 1999;354(9178):556-560. DOI: 10.1016/S0140-6736(99)022205 .

58. Kumar A, Thota $\mathrm{V}$, Dee $\mathrm{L}$, et al. Tumor necrosis factor alpha and interleukin 1 beta are responsible for in vitro myocardial cell depression induced by human septic shock serum. J Exp Med 1996;183(3):949-958. DOI: 10.1084/jem.183.3.949.

59. Kumar A, Brar R, Wang P, et al. Role of nitric oxide and cGMP in human septic serum-induced depression of cardiac myocyte contractility. Am J Physiol 1999;276(1 Pt 2):R265-R276. DOI: 10.1152/ ajpregu.1999.276.1.R265.

60. Thiru Y, Pathan N, Bignall S, et al. A myocardial cytotoxic process is involved in the cardiac dysfunction of meningococcal septic shock. Crit Care Med 2000;28:2979-2983. DOI: 10.1097/00003246200008000-00049.

61. Britto J, Nadel S, Habibi P, et al. Gastrointestinal perforation complicating meningococcal disease. Pediatr Infect Dis J 1995;14(5):393-394. DOI: 10.1097/00006454-199505000-00012.

62. Gedde-Dahl TW, Hoiby EA, Schillinger A, et al. An epidemiological, clinical and microbiological follow-up study of incident meningococcal disease cases in Norway, winter 1981-1982. Material and epidemiology in the menOPP project. NIPP Ann 1983;6(2): $155-168$.

63. Jones DM, Mallard RH. Age incidence of meningococcal infection England and wales, 1984-1991. J Infect 1993;27(1):83-88. DOI: 10.1016/0163-4453(93)93978-D.

64. Dass Hazarika R, Deka NM, Khriem AB, et al. Invasive meningococcal disease- an analysis of 110 cases from a tertiary care centre in north east india. IJP 2013;80(5):359-364. DOI: 10.1007/s12098-0120855-0.

65. Hodgetts TJ, Brett A, Castle N. The early management of meningococcal disease. J Accid Emerg Med 1998;15(2):72-76. DOI: 10.1136/emj.15.2.72.

66. Strelow VL, Vidal JE. Invasive meningococcal disease. Arq Neuropsiquiatr 2013;71(9-B):653-658. DOI: 10.1590/0004282X20130144.

67. Huang H-R, Chen H-L, Chu S-M. Clinical spectrum of meningococcal infection in infants younger than six months of age. Chang Gung Med J 2006;29(1):107-113.

68. Meningococcal disease (Neisseria meningitidis) - Case classification, National Notifiable Disease Surveillance System (NNDSS), www.cdc. gov, Last updated 2015.

69. Hart CA, Thomson APJ. Meningococcal disease and its management in children. BMJ 2006;333(7570):685-690. DOI: 10.1136/ bmj.38968.683958.AE.

70. Branco RG, Amoretti CF, Tasker RC. Meningococcal disease and meningitis. J Pediatr (Rio J) 2007;83:S46-S53. DOI: 10.2223/ JPED.1612

71. Wells LC, Smith JC, Weston VC, et al. The child with a nonblanching rash: how likely is meningococcal disease? Arch Dis Child 2001;85(3):218-222. DOI: 10.1136/adc.85.3.218.

72. Marzouk O, Thomson APJ, Sills J, et al. Features and outcome in meningococcal disease presenting with maculopapular rash. Arch Dis Child 1991;66(4):485-487. DOI: 10.1136/adc.66. 4.485 . 
73. Pollard AJ, Britto J, Nadel S, et al. Emergency management of meningococcal disease. Arch Dis Child 1999;80(3):290-296. DOI: 10.1136/adc.80.3.290.

74. Riordan FAl, Thompson APJ, Sills JA, et al. Prospective study of door to needle time in meningococcal disease. J Accid Emerg Med 1998;15(4):249-251. DOI: 10.1136/emj.15.4.249.

75. Visintin C, Mugglestone MA, Fields EJ, et al. Management of bacterial meningitis and meningococcal septicaemia in children and young people: summary of NICE guidance. BMJ 2010;340(c3209):C3209. DOI: 10.1136/bmj.c3209.

76. Mortensen JE, Gerrety MJ, Gray LD. Surveillance of antimicrobial resistance in Neisseria meningitidis from patients in the Cincinnati tristate region (Ohio, Kentucky, and Indiana). J Clin Microbiol 2006;44(4):1592-1593. DOI: 10.1128/JCM.44.4.1592-1593.2006.

77. Vázquez JA, Enriquez $R, A$ bad $R$, et al. Antibiotic resistant meningococci in Europe: any need to act? FEMS Microbiol Rev 2007;31(1):64-70. DOI: 10.1111/j.1574-6976.2006.00049.x.

78. Manchanda V, Bhalla P. Emergence of non-ceftriaxone-susceptible Neisseria meningitidis in india. J Clin Microbiol 2006;44(11): 4290-4291. DOI: 10.1128/JCM.01903-06.

79. Singhal S, Purnapatre KP, Kalia V, et al. Ciprofloxacin-resistant Neisseria meningitidis, Delhi, india. Emerg Infect Dis 2007;13(10):1614-1616. DOI: 10.3201/eid1310.060820.

80. Tunkel AR, van de Beek D, Scheld WM. Acute meningitis. Mandell, Douglas, and Bennett's Priciples and Practice of Infectious Diseases, 7th ed., Churchill Livingstone, Elsevier; 2010. pp. 1189-1229.

81. Stephens DS, Greenwood B, Brandtzaeg P. Epidemic meningitis, meningococcaemia and Neisseria meningitidis. Lancet 2007;369(9580):2196-2210. DOI: 10.1016/S0140-6736(07) 61016-2.

82. DeKleijn ED, Joosten KF, Van Rijn B, et al. Low serum cortisol in combination with high adrenocorticotrophic hormone concentrations are associated with poor outcome in children with severe meningococcal disease. Pediatr Infect Dis J 2002;21(4): 330-336. DOI: 10.1097/00006454-200204000-00013.
83. Takac l, Kvolik S, Divkovic D, et al. Conservative surgical management of necrotic tissues following meningococcal sepsis: case report of a child treated with hyperbaric oxygen. Undersea Hyperb Med 2010;37(2):95-99.

84. Dass R, Barman H, Duwarah SG, et al. Immune complex reaction after successful treatment of meningococcal disease: an excellent response to IVIG. Rheumatol Int 2013;33(1):231-233. DOI: 10.1007/ s00296-010-1555-6.

85. Stiehm RE, Damrosch DS. Factors in the prognosis of meningococcal infection. Med Prog 1966;68(3):457-467.

86. Thomson AP, Sills JA, Hart CA. Validation of Glasgow meningococcal septicaemia prognostic score: a 10 year retrospective study. Crit Care Med 1991;19(1):26-30. DOI: 10.1097/00003246-199101000 $-00010$.

87. Naeini AE. Importance of scoring systems in prognosticating meningococcaemia. J Res Med Sciences 2005;1:34-37.

88. Bilukha OO, Rosenstein N. National center for infectious diseases CDC, prevention. Prevention and control of meningococcal disease. Recommendations of the advisory committee on immunization practices (ACIP). MMWR Recomm Rep 2005;54(RR-7):1-21.

89. Antimicrobial prophylaxis- Meningococcal meningitis. Meningitisprevention of secondary cases of meningococcal meningitis/ septicaemia. East Kent Hospital University, NHS Foundation Trust. http://www.ekhuft.nhs.uk/staff/clinical/antimicrobial-guidelines/ antibiotic-prophylaxis/meningitis-prophylaxis/meningococcalmeningitis/.

90. Cohn AC, MacNeil JR, Clark TA, et al. Prevention and control of meningococcal disease: recommendations of the advisory committee on immunization Practices (ACIP). MMWR 2013;62(RR02):1-22.

91. Balasubramanium S, Shah A, Pemde HK, et al. Indian academy of pediatrics (IAP) advisory committee on vaccines and immunization Practices (ACVIP) recommended immunization schedule (20182019) and update on immunization for children aged 0 through 18 years. Indian Peds 2018;55:1066-1074. DOI: 10.1007/s13312-0181444-8. 